\title{
AN OVERVIEW OF A SYSTEMS MODEL OF CASSAVA AND CASSAVA PESTS IN AFRICA
}

\author{
A. P. Gutierrez ${ }^{1}$, B. Wermelinger ${ }^{1,2}$, F. Schulthess ${ }^{3}$, J. U. Baumgärtner ${ }^{2}$, J. S. YanineK ${ }^{3}$, \\ H. R. Herren ${ }^{3}$, P. Neuenschwander ${ }^{3}$, B. Lohr ${ }^{3}$, W. N. O. Hammond, ${ }^{3}$ and C. K. Ellis ${ }^{1}$ \\ ${ }^{1}$ Division of Biological Control, University of California, Berkeley, USA; ${ }^{2}$ Institut fur Phytomedizin, \\ ETH, Zurich, Switzerland; ${ }^{3}$ International Institute of Tropical Agriculture, Ibadan, Nigeria
}

\author{
(Received 10 March 1987)
}

\begin{abstract}
A systems model is described for cassava, Manihot esculenta Crantz, two of its introduced herbivores, the cassava green mite (CGM), Mononychellus tanajoa (Bondar), sensu lato, and the cassava mealybug (CM), Phenacoccus manihoti Mat.-Ferr., the introduced CM parasitoid, Epidinocarsis lopezi (DeSantis) and coccinellid predator of the genus Hyperaspis. The systems model includes the effects of weather, soil nitrogen and water levels on the interactions of the system's components.

The model simulates the distribution of developmental times of cohorts initated at the same time, as well as the number and biomass (energy) dynamics of all populations over time. Biomass acquisition and allocation at the population and organism subunit levels (e.g. leaves, fruit, ova) were also simulated. A common acquisition (i.e. functional response) submodel was used to estimate daily photosynthetic as well as nitrogen and water uptake rates in cassava, in addition to herbivory, parasitism and predation rates for the arthropod species.

This paper presents an overview of the systems model. Simulation results for the plant under pest free conditions were compared to field data. In addition, the model was used to estimate tuber yield losses due to CM and CGM feeding, and to examine the beneficial effects of introduced CM natural enemies as measured by reductions in tuber yield losses.
\end{abstract}

Key Words: Cassava systems model, Phenacoccus manihoti, Mononychellus tanajoa, Epidinocarsis lopezi, Hyperaspis spp.

Résumé - Un modèle de système est décrit pour le manioc, pour deux des herbivores introduits de cette culture (l'acarien vert (CGM), Mononychellus tanajoa (Bondar) sensu lato, et la cochenille farineuse du manioc (CM) Phenacoccus manihoti Mat.-Ferr, pour le parasitö̈de (Epidinocarsis lopezi (DeSantis)) introduit de la cochenille ainsi que pour une coccinelle prédatrice (Hyperaspis spp.) de la cochenille. Ce modèle de simulation tient compte des effets du climat, de l'azote et du régime hydrique du sol sur les interactions entre les composantes du système.

Le modèle simule la répartition des temps de développement de cohortes entamées au même moment, ainsi que la dynamique du nombre et de la biomasse (de l'énergie) de toutes les populations au fil du temps. L'acquisition et la répartition de la biomasse au niveau de la population et des sous-unités intra-organismes (ex. feuilles, fruits, oefs) ont été également simulées. En vue d'estimer les taux quotidiens de photosynthèse, d'absorbtion d'azote et d'eau, d'herbivorisme, de parasitisme et de prédation pour les espèces d'arthropodes, un sous-modéle commun d'acquisition (c'est-à-dire de réponse fonctionelle) a été utilisé.

Ce document présente une vue d'ensemble de ce modèle de système. Les résultats de la simulation pour les plantes non infestées ont été comparés aux données enregistrées en champ. En outre, le modèle a servi à estimer les pertes de rendement en tubercules dues à la cochenille et à l'acarien vert, ainsi qu'à observer les effets bénéfiques de l'introduction des ennemis naturels de la cochenille, en mesurant les réductions enregistrées dans les pertes de rendement en tubercules.

\section{INTRODUCTION}

Cassava, Manihot esculenta Crantz; Euphorbiaceae is a species native to South America that was introduced to Africa in the 1600 's where it quickly became an important staple food. During the past 16 years, two important pests, the cassava green mite (CGM), Mononychellus tanajoa (Bondar) sensu lato (Acari: Tetranychidae), and the cassava mealybug (CM), Phenacoccus manihoti Mat.-Ferr. (Homoptera, Pseudococcidae) were accidentally introduced into Africa, causing yield reductions of $30-80 \%$.

Chemical control of cassava pests was not ecologically, economically nor logistically feasible. Longerterm solutions for the control of CM and CGM were required, hence the Africa-wide Biological Control Programme for Cassava Pests (ABCP) was begun at the International Institute of Tropical Agriculture (IITA), Ibadan, Nigeria to meet this challenge. Biological control of $\mathrm{CM}$ has advanced considerably since the first establishment of the exotic parasitoid Epidinocarsis lopezi (DeSantis) (Herren and Lema, 1982). This parasitoid has now spread over much of the African cassava belt (Herren et al., 1987). However, the cassava green mite remains unchecked.

The overall goals of the systems analysis component of the ABCP were to help focus the research effort, to examine the dynamics of the various components of the cassava system, to estimate the effects of CGM and CM on tuber yields, to examine the 
effects of natural enemies (i.e., the exotic parasitoid $E$. lopezi and indigenous coccinellid predators of the genus Hyperaspis) on CM dynamics in conjunction with the effects of abiotic factors (temperature, rainfall, solar radiation, soil nitrogen and water) on the dynamics and interactions of the different species. The system components and their interactions are shown in Fig. 1.

In this paper, an overview of the systems model is presented only from a biological point of view. To lay a complete mathematical foundation for the model would be beyond its scope. The details of this model and a complete analysis of cassava growth, development and yield formations as influenced by its interactions with weather, pests and natural enemies are presented in detail later.

\section{POPULATION DYNAMICS MODEL}

Development of crop system models is becoming commonplace (Gutierrez and Wang, 1976; Wang et al., 1977; Curry et al., 1978; Brown et al., 1985; Gutierrez et al., 1975, 1976, 1987; and Baumgärtner et al., 1986). In this work a distributed delay model (cf. Manetsch, 1976; Vansickle, 1977) modified by Gutierrez and Baumgärtner (1984a, b) and Gutierrez et al. $(1976,1987)$ was used to simulate the population dynamics of all species as well as the nitrogen economy and water balance of cassava. The model is driven by observed weather and simulates the number and mass dynamics of each species including age structure; mimics the distribution of cohort developmental times; and incorporates the time-varying effects of energy supply/demand on birth, death, emigration, immigration, and growth rates of all species. An important aspect of this model is the notion that each population must acquire resources, and the rate of acquisition relative to their demand for assimilates determines whether the population grows or declines. A full discussion of the characteristics of this model are given in Gutierrez and Baumgärtner (1984a).

\section{Resource acquisition: carbon, nitrogen and water}

The process of photosynthesis in plants to acquire the energy (supply of carbon) required for growth and development (i.e. demand), and the processes of herbivory and predation (parasitism) are conceptually similar (Gutierrez et al., 1981). The functional response model is normally used to describe the relationship between the rate of prey capture per predator and prey density. Here we use it to estimate the rate of energy acquisition of one trophic level from a lower one. Leaves seek light, herbivores seek plants or plant parts, and carnivores (parasitoids and predators) seek prey (hosts). The processes of nitrogen $(\mathrm{N})$ and water uptake by plants may likewise be viewed as predation processes as roots seek both requisites. These analogies have been explored by Gutierrez et al. (1987). The shape of the functions describing the relationship between requisite capture (i.e. the supply) and that available in the environment is upwards convex (i.e. a type II functional response from predation theory).

Historically, we have used the Frazer-Gilbert (1976) functional response model to describe these relationships because of its property that the demand rate (see below) is the major driving variable determining the acquisition or supply rate under the prevailing conditions of resource availability and weather. Gutierrez et al. $(1981,1984 b, 1987)$ used this model to predict photosynthetic rates in plants, as well as predation and herbivory rates in arthropods. Here it has been extended to predict water and nitrogen acquisition rates in cassava.

In this paper, we emphasize the cassava model, but the principles apply equally to the other trophic levels shown in Fig. 1.

\section{Parameters for the Frazer-Gilbert Model}

The F-G model is the resource acquisition model. The F-G model estimates the birth rate of new biomass or individuals into, say, the $j$ th population (or trophic level), but at the same time it estimates the

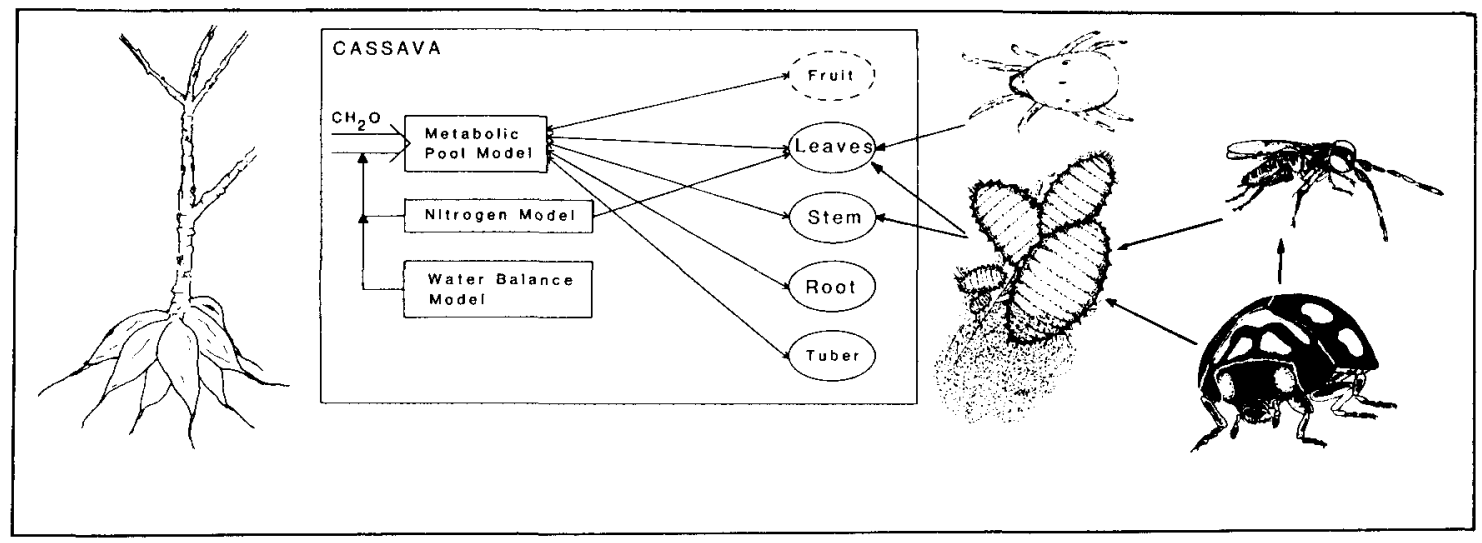

Temperafure, Solar Radiation, Nitrogen and water

Fig. 1. The cassava systems model for Africa. 
death rate or loss of biomass or numbers from the $j-1$ th population.

Resource base. The energy resource base for plants (e.g. cassava) is the light incident on its growing space, while the nitrogen (nitrates) and water in the maximum soil volume are the resources sought by the roots. For consistency of units, the light energy falling per unit area $\left(\mathrm{cal} / \mathrm{cm}^{2} /\right.$ day) may be converted to dry matter equivalents using theoretical values reported by Loomis and Williams (1963, see Gutierrez et al., 1987).

For CGM, the resource base is the quantity of suitably aged leaf matter; for the $C M$ it is the quantity of available plant sap; for the parasitoid $E$. lopezi, it is the number of suitably aged $\mathrm{CM}$ in its search space; for the coccinellid predator, it is the mass of unparasitized and active parasitized CM life stages plus all coccinellid larvae younger than the one considered. Hyperaspis spp. are among the most abundant indigenous CM predators (Neuenschwander et al., 1987). Since their biologies have not been studied in much detail, life-table data were instead taken from a study on $H$. jucunda Muls. (She, 1985).

The demand rate. The species demand rate is a measure of what an organism of a population needs to grow at the maximum rate, but it is the environment that determines how much of the available resource it can acquire (supply). For plants, the maximum assimilation rates of photosynthate (carbon) for growth, reproduction, reserves and respiration is the demand rate, while the photosynthetic rate is the realized supply rate (Gutierrez et al., 1975). The nitrogen demand is a fraction of the carbon demand, and the demand for water is the maximum evapotranspiration rate. The maximum demand rates may be estimated from plants grown under nonlimiting conditions. Similar analogies can be made for arthropods, and their demand rates can also be estimated by growing them under nonlimiting conditions. In all our models, the interplay between supply and demand determines the growth, birth, death and net immigration rates, and developmental rates.

Searching. All organisms search in one way or another for their requisites, and search is an important component of the F-G model. In plants, the proportion of light that falls on a leaf surface increases exponentially with increasing leaf area index (LAI) (i.e. a type II function, Evans, 1975). This function is used to estimate the search parameter in the F-G model. LAI is an index of the leaf surface area relative to the area the plant may occupy. Leaf area is a linear function of leaf mass. The F-G search parameter for the nitrogen and water models corresponds to that for light, and hence assumes that the efficiency of the below ground search proceeds in parallel with that above ground.

In predation (also parasitism and herbivory) theory, it is assumed that the proportion of the search space examined increases with predator size at the per capita level, and with total predator mass at the population level. Leaves may be thought of as light predators whose search efficiency drops off with age. The rate of search and the model for predators, parasitoids and herbivores is thus of the same form as the search model of leaves for light.

The search model described above, known as a
Montieth function in plant physiology, is the same as the Nicholson-Bailey model of animal ecology (Gutierrez and Wang, 1976). In our systems model, it is a parameter of the F-G model. The F-G model is sensitive to the value of the search parameter only at low levels of resource (i.e. prey).

\section{Within trophic level resource allocation}

Carbon. Carbon fixed (energy) from photosynthesis or predation and herbivory is allocated in the model according to the following priority scheme: first to respiration (and egestion where appropriate), then reproduction and lastly to growth and reserves (Gutierrez et al., 1975, 1986; Wang et al., 1977). In all species, energy acquisition and allocation link the organism population model to its subunit models (e.g., fruits, leaves or embryos; Gutierrez et al., 1976; Jones et al., 1974). The production rates of new subunits and the growth rates of existing ones are functions of the ratio of energy supply/demand (index), as are intrinsic death and net immigration rates.

Nitrogen. The model for the allocation of nitrogen (N) by plants is similar to that for carbon except that respiration costs in units of nitrogen are not assessed. These costs are included in the carbon balance model. The nitrogen supply/demand index is a measure of the health of the plant. In our model, it scales the photosynthetic rate thus affecting the supply side of the carbon index and all rates associated with it (see above). The concentration of $\mathrm{N}$ in plant parts and its reallocation from older structures to new ones was also modelled.

The balance of $\mathrm{N}$ in the soil is the net of that which decays from organic matter, is fixed by other organisms, is added as fertilizers or input in other ways, and is taken up by the plant. The rate of $\mathrm{N}$ uptake is also affected by water stress, and in the model this rate is scaled by the water supply demand index (see below).

Nitrogen in plant parts may also have a large impact on the growth and development of arthropods feeding on them. Some published plant models (e.g. Jones et al., 1974; Brown et al., 1985) include this important effect on plant populations, but not its effect on the pests. The effects of leaf $\mathbf{N}$ on twospotted mites fecundity, longevity and survivorship was clearly shown by Wermelinger et al. (1985), and these effects have been extended to CGM and CM population dynamics.

Water. An adequate supply of water is required to maintain cell turgor and metabolism, transpiration for temperature regulation and to guarantee the flow of nutrients (e.g. N) from the soil to the metabolically active sites in the plant. Most crops are not well adapted to drought, and shortage of water leads in most plants to reduced photosynthesis and growth, and death in extreme cases. Cassava is thought to be drought resistant, but it is extremely susceptible to excess water (Connor et al., 1981). Positive responses to irrigation have been shown, especially during the first couple of weeks after planting (Cock and Reyes, 1985).

Water concentration in the plant is not modelled, rather only the relationship between the evapotranspiration demand rate, estimated by using the Ritchie (1972) model and the supply, estimated by 
using the water version of the F-G model, are considered. The evapotranspiration demand from the Ritchie model is the major parameter driving the water version of the F-G model. The water supply/ demand index scales the nitrogen uptake rate, and also the photosynthetic rate.

The water in the root zone is balanced daily, and is the net of precipitation, irrigation, evaporation from the soil surface, run-off, and that taken up by the plant. The water (and $N$ ) available to the plant is determined by root depth and the amount of water in the soil above the permanent wilting point (Connor et al., 1981). The soil volume is not modelled as layers, rather the water is considered to be in a tank which plants can access according to their current root envelope. Other analysts have used fine grid maps of the soil profile to model water availability, but such models require much information that is not usually available and are computation intensive. Our simple approach proved quite adequate.

\section{PLANT GROWTH DATA}

The extensive field data on the growth and development of the three branch IITA cassava variety TMS 30572 collected by one of us (FS) during the 1983-1984 seasons at the International Institute of Tropical Agriculture (IITA), Ibadan, Nigeria were used to estimate parameters for the cassava model. Cassava cuttings $(12 \mathrm{~g})$ were put in the field at a density of $1 \times 1 \mathrm{~m}$ on 15 May 1983 at the beginning of the rainy season when the soil moisture level was high. Eight to 10 plants were dug up weekly, and dissected into leaves, stems, tubers and roots, and dried. Cassava fruit mass is very small relative to the total weight of the plant $(2.32 \pm 1.12 \mathrm{~g}$ vs $3000+\mathrm{g}$ dry matter), and is not considered in the model. Weather data from the IITA central weather station were used to drive the simulation model. Time and age in the model are expressed in degree days (DD).

In the model, stem, root and tuber growth demands were related to the maximum growth rate of leaves. A leaf is usually produced at each stem node, hence the leaf production rate and their mass growth rates can be easily estimated from the field data. The total demand for growth of leaves at time $t$ is the sum of the products of the frequency of different aged leaves times their maximum age-specific growth demand rates. The realized growth rates and the leaf production rates are scaled by the carbohydrate supply/demand index. The time of branching is determined by the ratio of carbohydrate supply plus reserves to demand.

The parameters for the arthropod models are similarly estimated, but the estimation procedures are not discussed here.

\section{SIMULATION RESULTS}

\section{Cassava}

The observed and simulated patterns of leaf, stem plus root and tuber dry matter are shown in Fig. 2A (cf., Fig. 9 in Gutierrez et al., 1987). The simulation results compared well to the field data of 1983/84. The leaf dry matter increased to approximately $220 \mathrm{~g} /$ plant, then leveled off when the rate of leaf production equaled the rate of abscission. Still later, the quantity of leaves declined as the rate of leaf production fell below the rate of senescence and abscission. This occurred because the quantity of respiring tissues continued to increase after the leaf canopy had reached its maximum LAI, thus creating an increasing shortfall of photosynthate. This photosynthate (carbohydrate) stress caused a slowdown in the rate of dry matter accumulation in stem plus root, tubers and reserve. Late season water and nitrogen stress also acted to reduce photosynthetic rates at ca. $3100 \mathrm{DD}$. The patterns of dry matter accumulation in stem plus root and tubers are very similar, with $3.7 \%$ more accumulating daily in tubes. The growth rate of the plant more than doubled at about 900 degree days (DD), when the exponential growth phase began.

The daily partitioning patterns of dry matter are shown in Fig. 2B, and the cumulative values are shown $2 \mathrm{C}$. The results suggest that the partitioning coefficients for photosynthate allocation to all vegetative parts are constants after respiration costs are subtracted. The model further suggests that tuber and stem growth have the same priority as vegetative growth, but both may be used in times of carbohydrate stress. This is not new, rather it is reassuring to confirm it. All attempts to redefine the above priorities produced poor simulation results.

\section{Other system components}

In practice, the impact of each component on the system would be examined separately, and the interaction mapped to obtain an overview of the possible range of responses. That is not possible in this paper, but some general results of the more detailed studies are reported.

Water and nitrogen effects. Water and nitrogen stress in the 1983-1984 crop studied reduced yield ca. 2 and $6 \%$, respectively, but this effect occurred late in the season. In simulation studies, increasing water stress causes abrupt changes in tuber growth patterns caused by defoliation. Nitrogen stress caused a more gradual slowdown in tuber growth rates. Changes in leaf quality occurred in response to changes in soil $\mathrm{N}$, reallocation from older leaves, and the direct effects of water stress on $\mathrm{N}$ uptake. Reductions in leaf $\mathrm{N}$ increase with plant and leaf age. Reduced $\mathrm{N}$ concentrations negatively affected CGM and CM population growth rates via reduced fecundity, longer developmental times and decreased survivorship.

Biological control of cassava pests. A simulation of the interaction of the systems components illustrated in Fig. 1 is shown in Fig. 3, and illustrates just a small part of the biological detail included in the model. The expected yield losses due to the two pests as modified by the other systems components are indicated in the figure as shaded areas. Other studies showed that $\mathrm{CM}$ is potentially more damaging than CGM.

In this study, the CM population was started 50 days after planting and its parasitoid and predator were started on day 150. CGM populations were started 170 days after planting at the onset of the dry season. Rainfall mortality suppressed CM populations before the dry season period of increase, but the natural enemies quickly suppressed them after that 

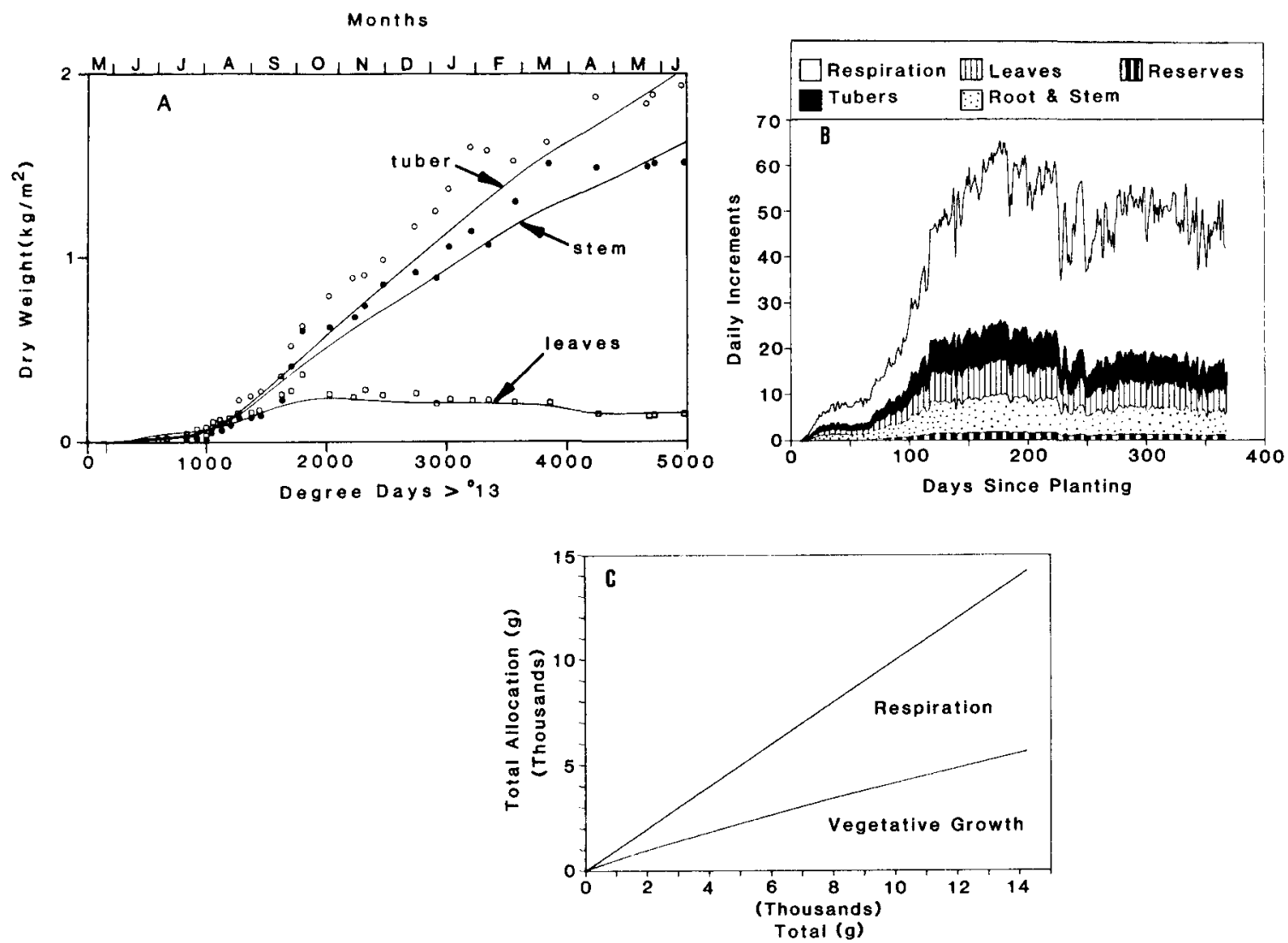

Fig. 2. Simulated and observed dry matter patterns in cassava: A. simulation of dry matter accumulation, B. daily allocation patterns, and C. cumulative allocation ratios (cf., Gutierrez et al., 1987).

time. Other simulations showed that the same degree of control could be expected from the parasitoid alone, suggesting that the predators contribution to $\mathrm{CM}$ mortality was dispensable. This agrees with field observations. Starting the parasitoid earlier in time merely reduced $\mathrm{CM}$ populations more quickly.
An explanation of why the host specific parasitoid E. lopezi alone is capable of quickly suppressing the $\mathrm{CM}$ population emerged. Among the factors which contribute are the fact that the parasitoid prefers to attack older CM life stages in which a maximum investment in time and energy has been made. Not

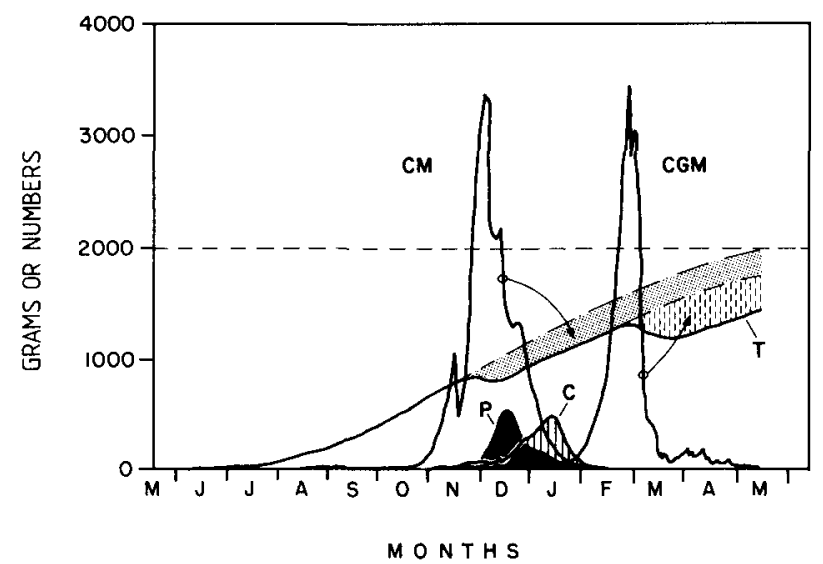

Fig. 3. The simulated dynamics of cassava tuber production ( $\mathrm{g}$ dry matter; $\mathrm{T}$ ) as influenced by cassava mealybug $(\mathrm{CM})$, cassava green mite $(\mathrm{CGM})$ populations $\left(\times 10^{-2}\right)$, Epidinocarsis lopezi $(\mathrm{P})$, and the coccinellid predator Hyperaspis $(\times 10)(C)$ as well as weather $(1982-1983)$ at IITA, Ibadan, Nigeria.

Estimated cassava yield losses due to CM and CGM damage (shaded areas) are indicated. 
only are the individuals attacked killed, but also the progeny that they would have shortly produced. A greater proportion of parasitoid females are produced in older $\mathrm{CM}$ further mitigating against $\mathrm{CM}$ population growth. Lastly the parasitoid feeds on all host stages, perhaps enabling it to extend its survival time in the absence of suitable hosts for oviposition.

In contrast, the predator has a high consumption rate, but requires a considerable period of time for its numerical response to suppress $\mathrm{CM}$ populations. It has a relatively high requirement for maintenance respiration before egg production can begin and is thought to leave the field when prey levels fall below this maintenance level. Rainfall mortality may reduce CM populations to a level low enough to cause the predator and the $\mathrm{CM}$ populations to disengage. In the presence of the parasitoid's attack, low CM populations are commonplace and appear to have resulted in the displacement of native coccinelid predators (Neuenschwander et al., this Issue). Greater tuber yield losses are predicted when the predator as opposed to the parasitoid attack the same initial CM populations.

Effective natural enemies of the cassava green mite have not been released in Africa. Hence, as Yaninek et al. (this issue) have shown, rainfall is the major factor limiting CGM population growth during the rainy season as indicated by their delayed buildup.

Low levels of leaf nitrogen may slow CGM population growth rates at all times of the year. Increasing levels of defoliation due to drought stress also cause increasingly severe abrupt disruptions of CGM populations. The model suggests that CGM damage would be lower on nitrogen poor soils and that combining fertilization and irrigation in arid areas should produce much higher CGM populations.

\section{REFERENCES}

Baumgärtner J., Graf B., Zahner Ph., Genini M. and Gutierrez A. P. (1986) Generalizing a population model for simulating "Golden Delicious" apple tree growth and development. Acta hortic. 184, 111-122.

Brown L. G., Jones J. W., Hesketh J. D., Hartsog J. D., Whisler F. D. and Harris F. A. (1985) Cotcrop: computer simulation of cotton growth and yield. Miss. Agric. \& Forest Exp. Stn., Info. Bull. 69.

Connor D. J., Cock J. H. and Parra G. E. (1981) Response of cassava to water shortage. 1. Growth and yield. Field Crops Res. 4, 181-200.

Cock J. H. and Reyes J. A. (1985) Cassava: Research Production and Utilization. UNDP/CIAT.

Curry G. L., Feldman R. M. and Smith K. C. (1978) A stochastic model of a temperature-dependent population. J. Theor. Biol. 13, 197-204.

Evans L. T. (1975) Crop Physiology-Some Case Histories. Cambridge University Press, Cambridge, Mass.

Frazer B. D. and Gilbert N. (1976) Coccinellids and aphids: a quantitative study of the impact of adult ladybirds (Coleoptera: Coccinellidae) preying on field populations of pea aphids (Homoptera: Aphididae). J. Ent. Soc. Brit. Columb. 73, 33-56.

Gutierrez A. P. and Baumgärtner J. U. (1984a) Multitrophic level models of predator-prey energetics: 1. Age-specific energetic models - pea aphid Acyrthosiphon pisum (Harris) (Homoptera: Aphididae) as an example. Can. Ent. 116, 924-932.

Gutierrez A. P. and Baumgärtner J. U. (1984b) Multitrophic level models of predator-prey energetics: II. A realistic model of plant-herbivore-parasitoid-predator interactions. Can. Ent. 116, 933-949.

Gutierrez A. P., Baumgärtner J. U., and Hagen K. S. (1981) A conceptual model for growth, development and reproduction in the ladybird beetle, Hippodamia convergens (Coleoptera: Coccinellidae). Can. Ent. 113, 21-33.

Gutierrez A. P., Christensen J. B., Merritt C. M., Loew W. B., Summers C. G. and Cothran W. R. (1976) Alfalfa and the Egyptian alfalfa weevil (Coleoptera: Curculionidae). Can. Ent. 108, 635-648.

Gutierrez A. P., Falcon L. A., Loew W., Leipzig P. A. and van den Bosch R. (1975) An analysis of cotton production in California: a model for Acala cotton and the effects of defoliators on its yield. Environ. Ent. 4, 125-136.

Gutierrez A. P., Schulthess F., Wilson L. T., Villacorta A. M., Ellis C. K. and Baumgärtner J. U. (1987) Energy acquisition and allocation in plants and insects. Can. Ent. $119,109-129$.

Gutierrez A. P. and Wang Y. H. (1976) Applied population ecology models for crop production and pest management. In Pest Management, International Institute for Applied Systems Analysis (Edited by Norton G. A. and Holling C. S.), pp. 255-280. Proc. Ser.

Herren H. R. and Lema K. M. (1982) First successful releases. Biocontrol News and Infor., C.A.B. 34, 185.

Herren H. R., Neuenschwander P., Hennessey R. D. and Hammond W. N. O. (1987) Introduction and dispersal of Epidinocarsis lopezi (Hym., Encyrtidae), an exotic parasitoid of the cassava mealybug, Phenacoccus manihoti (Hom., Pseudococcidae), in Africa, Agric. Ecosystems Envir. (in press).

Jones J. W., Thompson A. C. and Hesketh J. D. (1974) Analysis of SIMCOT: Nitrogen and growth. Proc. Belt wide Cotton Prod. Res. Conf., Memphis, pp. 111-116.

Loomis R. S. and Williams W. A. (1963) Maximum crop productivity: an estimate. Crop Sci. 3, 67-72.

Manetsch T. J. (1976) Time varying distributed delays and their use in aggregate models of large systems. IEEE Trans. Sys. Man Cybern. 6, 547-553.

Neuenschwander P., Hennessey R. D. and Herren H. R. (1987) Food web of insects associated with the cassava mealybug, Phenacoccus manihoti Matile-Ferrero (Hemiptera: Pseudococcidae), and its introduced parasitoid, Epidinocarsis lopezi (DeSantis) (Hymenoptera: Encyrtidae) in Africa. Bull. Ent. Res. 77, (in press).

Ritchie J. T. (1972) Model for predicting evaporation from a row crop with incomplete cover. Water Resource Res. 8, 1204-1213.

She, H. D. N. (1985). The bioecology of the predator Hyperaspis jucunda Muls. (Coleoptera: Coccinellidae) and the temperature responses of its prey, the cassava mealybug Phenacoccus manihoti Mat.-Ferr. (Homoptera: Pseudococcidae). Ph.D. thesis, Univ. Ibadan, Nigeria, $300 \mathrm{pp}$.

Vansickle J. (1977) Attrition in distributed delay models IEEE Trans. Syst., Man, and Cybern. 7, 635-638.

Wang Y. H., Gutierrez A. P., Oster G. and Daxl R. (1977) A population model for cotton growth and development: coupling cotton-herbivore interactions. Can. Ent. 109, $1359-1374$.

Wermelinger B., Oertli J. J. and Delucchi V. (1985) Effect of host plant nitrogen fertilization on the biology of the two-spotted spider mite, Tetranychus urticae. Ent. exp. appl. 38, 23-28. 